\title{
Analysis on Cross-Regional Land Ecological Compensation
}

\author{
Lijuan Zhou \\ School of Economic and Management, Sichuan Agricultural University \\ ChengDu, 611130, China \\ Tel: 86-139-0808-8374Ｅ-mail: zhoulijuan1214@hotmail.com \\ Ruiping Ran (Corresponding author) \\ School of Economic and Management, Sichuan Agricultural University \\ ChengDu, 611130, China \\ Tel: 86-186-0287-3848 E-mail: ruipingran@yahoo.com.cn
}

Received: November 29, $2011 \quad$ Accepted: December 15, $2011 \quad$ Online Published: April 1, 2012

doi:10.5539/jas.v4n5p69

URL: http://dx.doi.org/10.5539/jas.v4n5p69

\begin{abstract}
This paper chose Eastern China area, Central China area, Western China area and Northeast China area as the study object and chose landuse classifications as the basic ecological system unit. It roughly estimated the regional ecological system service value. The theory of ecosystem service value, the method of ecological footprint and ecological carrying capacity are applied to analyze the cross-regional land ecological compensation problem, providing the theoretical guidance for the ecological environment protection and land ecological compensation quantification study.
\end{abstract}

Keywords: Land, Ecological compensation, Ecological service value

\section{Introduction}

\subsection{Topic Background}

Ecological environment provides human with ecological products and services through ecological system, supporting the existence and development of human society. However, the features and values of the ecological environment are not fully known to people in social and economic activities. The environment destruction and pollution are getting more and more serious along with the rapid development of the economy and the society, which arouses people's stronger desire to protect the ecological environment as well as implement the sustainable development strategy. Certain regional differences of the economic development and environmental protection caused certain inequality between the areas. The differences are mainly reflected in the following three aspects:

First of all, the area where economy developed relatively more rapidly often consumes more ecological resources. In order to develop the regional economy, it not only consumes its own ecological resources, but also exploits the resources of other areas which need to pay for the pollution cost caused by developing resources;

Second, in order to reduce its pollution, people in the developed areas set their factories in the ecologically fragile region thus strengthening ecological environmental pressure on the ecologically fragile regions;

Third, the economically developed area may be the biggest beneficiaries of ecological management while the area making the "ecological contribution" is often ecologically fragile region (and is often the underdeveloped area).If the ecologically fragile region sacrifices certain economic interests to make ecological construction, it is difficult to achieve the expected effect by only depending on the economic strength of the ecologically fragile region.

Therefore, studying the land ecological compensation across areas has important practical significance to coordinate the economic and ecological inequality and to make sure the ecological environment construction sustainable. 


\subsection{Literature Review}

In recent years, the ecological compensation mechanism has become a hot research subject in the field. Many scholars have made a lot of researches on the compensation range, compensation standard, compensation source and compensation method extensively.

Cao Mingde (2004) discussed the interest conflicts of the upper and the lower river basin, as well as the different position of the compensation system by studying the fields of the river and the forest ecological compensation. And then he put forward that the mechanism of ecological compensation is the concrete manifestation of natural resources principle.

Based on the frontiertheories and methods of ecosystem services and eco-footprint, Ceng Yuanquan, Ding Sibao, Wang Rongcheng (2010) proposed that it is particularly important to study ecological compensation for ecological compensation system from the angle of regional relationship and to establish a regional ecological compensation system for the sake of realizing the coordinated development of regional objectives through the corresponding regional policy measures.

Feng Yanfen, Liu Yihua, Wang Fang, Yang Muzhuang (2009) reviewed the progress of ecological compensation practice in recent years, introduced the main task and results of ecological compensation. Furthermore, the main problems in current ecological compensation practice were pointed out, such as lacking specific ecological compensation policy to achieve the compensation goal and lacking stakeholder participation, In addition, market compensation potential still needs to be improved, compensation standards were too low and the imperfect compensation mechanism made it difficult for the theories and technologies to be put into practice. Gao Wangsheng (2007) put forward the determinant standard for ecological compensation, accounting model and techniques to determine the amount of ecological compensation, and suggest that it is necessary to build up a national organization of ecological compensation fund to address the inconsistency between ecosystem services and eco-footprint.

Lai li, Huang Xianjin, Liu Weiliang (2008) analyzed and evaluated the advances in ecological compensation, including its concept, theory origin, criterion, mode and its domestic and international effect Furthermore, they pointed out that the deficiencies of domestic researches such as feasibility, effect evaluation, efficiency and detailed implement plan analysis should be improved.

Ma Aihui, Zhang Anlu (2009) analyzed the existing land ecological compensation mechanism and proposed a fair and effective public policy system through estimating the land ecological compensation standard, which provides the scientific basis for ensuring the rational land use and protecting the ecological environment.

Based on the theories and methods of ecological footprint and eco-capacity, Liu Qiang, Peng Xiaochun, Zhou Lixuan (2010) put forward the determinant standard for ecological compensation through calculating the ecological footprint and eco-capacity of every city in GuangDong Province. And the results indicated that the ecological footprint of each city is in the status of deficit and the most serious ecological deficit is in the Pearl River region. The cities which lie on development area of the Pearl River region need to pay ecological compensation to the cities of under development around it.

Ran Ruiping (2007) studied the main problems of ecological compensation system in the project of returning the grain plots to forest in China, and studied the experiences of ecological compensation system in Conservation Reserve Program (CRP) in America. Finally suggestions on ecologic compensation system in returning the grain plots to forest are worked out.

In the related studies of ecological compensation, there are many research methods about the ecological compensation standard, but so far, there is no standard method to calculate ecological compensation in the academic circles. The standard of the ecological compensation is the key and the difficult problem which determines whether the ecological compensation practice can be carried out or not. This paper tries to apply the theory and method of the ecological footprint and ecological system to analyze the ecological compensation of the eastern, western, central and northeastern areas in China, in the hope of promoting the rational land use , protecting the ecological environment, and providing a scientific basis for the land ecological compensation problem.

\section{Calculation of the Areas' Land Ecological Compensation}

\subsection{The Ecosystem Services Value of the Areas}

Ecosystem services mean that human get the interests from ecological system directly or indirectly, including 
that the ecological system inputs useful material and energy to the economic and social system, accepts and transforms the waste from human society, as well as provides services (such as clean air and water resources) to members of the human society directly. Only a fraction ecosystem service can enter the market to be traded in, and most of the ecosystem services can't enter the market because they are public or quasi public items, which is different from the traditional economic sense. In recent years, people have realized the important function of the ecological service, there are more and more studies about the function of the ecosystem services. But most values of the earth's ecological system service are difficult to quantify, so the theory and method of the value evaluation are still not mature. Constant $\mathrm{R}$ and other scholars published the research results of the global ecosystem services value on Nature in 1997, laid some foundation of the evaluation of the ecosystem services value. Researchers ChunxiaLu applied Costanza $\mathrm{R}$ estimation method to make out the factor table for Chinese ecological system service value equivalent, which established the unit area land service value table of the ecological system in China, as the following table 1. The Ecosystem service value formula is:

$$
V=\sum_{i=1}^{n} P_{i} * A_{i}(i=1,2, \cdots \cdots, n)
$$

In the formula, $\mathrm{V}$ represents the total value of ecosystem services of the research area; Pi represents the total value of ecosystem services of the unit area.

This paper divided China into four areas, the eastern includes ten provinces and cities like Beijing, TianJin, HeBei, ShanDong, GuangDong, HaiNan, ShangHai, JiangSu, ZheJiang, FuJian, the central area includes six provinces like the central Henan province, Hubei, Hunan, Shanxi, Anhui and Jiangxi province. The western area includes Chongqing, Sichuan, Guizhou, Yunnan, Tibet, Shanxi, Gansu, Qinghai, Xinjiang, Ningxia, Inner Mongolia, Guangxi, in total twelve provinces and cities in China. The northeast includes Liaoning, Jilin and Heilongjiang province. The ecosystem service value of the four areas can be obtained by the computation: the ecosystem service value of the eastern area was 882709.21 million yuan, the ecosystem service value of the northeast area was 806302.07 million yuan, and the ecosystem service value of the central area was 1137480.86 million yuan, the ecosystem service value was 2608143.62 million yuan. The eastern is the developed economic region, whose gross domestic product accounted for about $56 \%$ in tatal, more than half of the nation's GDP. The gross domestic product of the Northeast accounted for about $9 \%$, the central accounted for about $19 \%$, and the western accounted around $16 \%$.

It can be seen from the data that each regional economic development did not match with its ecological service value. The developed area developed resources extensively, making the ecological service value less and less. Because the whole social ecological system is constantly circulating and flowing, it also consumes the environment resources of other areas. However, the ecologically fragile areas in western China which was the key area of resources and environment protection were classified as national development zone and the limits of the forbidden zone. In order to improve the natural environment and protect the whole social ecological environment, they sacrificed the interests of the economic development. Therefore, the developed areas which have large resource consumption should compensate the ecologically fragile areas.

\subsection{The Ecological Footprint and Ecological Carrying Capacity of Different Areas}

Ecological footprint is a biologically productive region space that has the ability to provide the resources or absorb waste continually, an account tool that can measure a certain population or the size of the economy resources consumption and waste absorption level in productive land area. The calculation of the ecological footprint is mainly based on the following two facts: (1) human can estimate the quantity of their major consumption of resources, energy and waste in production; (2) these resources and waste material can be transferred into the ecological productive area that produce and consume these resources and waste material logistics. According to the difference of the productivity, the ecological footprint theory divided the land on the surface of the earth into six ecological productive classes: fossil energy, arable land, grassland, forest, built and waters.

Computation formula is as follows:

$$
E F=N * E F=N * r j * \sum_{i=1}^{n}\left(a * a_{i}\right)=N * r_{j} * \sum_{i=1}^{n} r_{j} *\left(C_{i} / P_{i}\right)(i=1,2, \cdots \cdots n, j=1,2, \cdots \cdots 6)
$$

In the formula, EF represents the ecological footprint; $\mathrm{N}$ represents population; $\mathrm{EF}$ represents the ecological footprint per capita; I represents the consumer products and the types; J represents the biological productive land 
types; a $\times$ ai represents the biological conversion land area per capita of kind I trades commodities for the productive; Ci represents the goods consumption per capita of kind i; Pi represents the world average production ability of consumer goods i. And biological resources consumption mainly includes food, vegetables, edible vegetable oil, pork, beef, mutton, eggs, milk and fruit; Energy consumption mainly includes coal and electric energy.

Ecological carrying capacity is the corresponding concept with ecological footprint. It is the area of the land ecological productive under the premise that does not damage the productivity and function of the ecosystem a region has. According to the advice of the Our Common Future, by deducing $12 \%$ of biological productive area that was used for biodiversity protection, humans can get the actual use of ecological carrying capacity.

The formula is: $E C=N * e c=0.88 \sum_{j=1}^{6}\left(a_{j} * r_{j} * y_{j}\right)(j=1,2, \cdots \cdots, 6)$

In the formula, EC represents the total ecological carrying capacity; $\mathrm{N}$ represents population; ec represents the ecological carrying capacity per capita; Aj represents the biological production area per capita; $\mathrm{Rj}$ represents the balanced factor.

By calculating, the ecological footprint of the eastern area was 19487.1274 (ten thousand per $\mathrm{hm}^{2}$ )and the ecological carrying capacity was 12948.55 (ten thousand per $\mathrm{hm}^{2}$ ); The ecological footprint of the northeast area was 4199.19 (ten thousand per $\mathrm{hm}^{2}$ )and the ecological carrying capacity was 21320.96 (ten thousand per $\mathrm{hm}^{2}$ ); The ecological footprint of the central area was 33178.34 (ten thousand per $\mathrm{hm}^{2}$ )and the ecological carrying capacity was32621.27 (ten thousand per $\mathrm{hm}^{2}$ ); The ecological footprint of western area was 15768.35 (ten thousand per $\mathrm{hm}^{2}$ )and the ecological carrying capacity was 30569.87 (ten thousand per $\mathrm{hm}^{2}$ ). These data show that the eastern and central regions were ecological deficit, the northeast and west areas present ecological surplus. All kinds of ecological system provide the consumption in northeast and west were surplus, and the surplus was offered to east and central regions. In order to achieve social welfare fairness, the ecological deficit area should provide ecological compensation to the ecological surplus area.

\subsection{The Ecological Compensation of Different Areas}

The ecological compensation across areas can't just rely on the different ecological value of the regions, it should determine the macro area ecological compensation quantitative problem based on comprehensive theories and methods of the ecological footprint and ecological service value.

The formula is:

$$
E C_{i}=E S_{i} * R_{i} * Q_{i}\left(R_{i}=G D P_{i} / G D P * Q_{i}=\left|E F_{i}-E C_{i}\right| / E C_{i}\right)
$$

ECi represents the ecological compensation amount the region pays or gets i; EFi represents the total ecological footprint of the 1 areas; Ri represents the economic adjustment coefficient; ECi represents the available ecological carrying capacity of the areas; Qi represents the input or output coefficient.

If $\mathrm{EC} \mathrm{i}>0$, the region should pay the ecological compensation;

If $\mathrm{ECi}<0$, the region can get the ecological compensation;

If $\mathrm{ECi}=0$, the area of supply and consumption was balanced and there's no need to pay or get the ecological compensation. Table 2 can be got by the calculation.

\section{Conclusions}

Seen from table 2, the ecological compensation of the eastern and central was positive. The two areas should pay ecological compensation. The ecological compensation of the northeast and the western area was negative as they should obtain the corresponding ecological compensation. Due to the strong local government and economy, the fierce competition and the significant differences in the development among areas, the ecological benefit areas' responsibility of paying compensation was not high. It is difficult to form the liability mechanism of ecological compensation. To solve the problem is to determine the direction of the ecological compensation mechanism, and to judge the external function of the regional ecological environment. If the big winner is the country, the central government should undertake the responsibility of the ecological compensation and to make contribution by the longitudinal financial ways such as transferring payments; If there is a clear beneficiary, it should pay the compensation in responsibility.

The land ecological compensation practice in China lacked flexibility and diversity and the compensation mode 
was rigid and simplex. The compensation fund is mainly government financed. Compensation funds can be obtained by collecting environmental tax from stakeholders or subsidy form. The ecological compensation across areas should follow the principle of "who benefits, who compensates". Emphasizing the parallel compensation between governments can not only reduce the government's financial pressure, but also stimulate the land ecological environment stakeholders' compensation cognition.

This paper estimated the ecological value based on related theories and methods of ecological footprints and ecological carrying capacity and analyzed the amount of the ecological compensation. But then, the result may be biased because the obtained data was not very complete, such as the water area. Because the ecological compensation was an effective coordination method for ecological environment protection and economic development, it is significant to set an ecological compensation standard. But how to set a more accurate and effective one still needs in depth exploration

\section{References}

CHEN, Yuan-quan, \& WANG, Sheng-gao (2007). Based on ecology theory and method of ecological compensation quantitative rsearch. The system engineering theory and practice, 4, 165-170.

CHENG, Tan-qiu. (2009). On the ecological compensation standards and mechanism. Annual and Environment, $38(6), 1-6$.

Cuperus R, Canters KJ, Udo DE Haes H A, et al. (1999). Guidelines for ecological compensation associated with highways. Bio-logical-Conservation, 90, 41-51. http://dx.doi.org/10.1016/S0006-3207(99)00007-5

MA Ai-hua. (2009). Ecological footprint theory and method of shallow development. China's land institute proceedings conference, 5, 39-43.

SEN, Xue. (2007). Western region ecological construction compensation mechanism. Sichuan agricultural university.

Tan, Qiu-cheng. (2009). On the ecological compensation standards and mechanism. Annual and Environment, 38 (6), 1-6.

YANG, Kai-zhong, \& YANG, Yong. (2008). ChenJie. Ecological footprint analysis theory and method. Progress of earth science, 6, 630-636.

YU, Hai, \& REN, Yong. (2008). Chinese ecological compensation: concept, type and policy path selection problem. China's soft science, 6, 7-15.

Table 1. The unit area land service value table of the ecological system in China(yuan $/ \mathrm{hm}^{2}$ )

\begin{tabular}{lllllll}
\hline & Forest & Lawn & Farmland & Wetland & Desert & Waters \\
\hline Gas & 3097 & 707.9 & 442.4 & 1592.7 & 0 & 0 \\
Climate & 2389.1 & 796.4 & 787.5 & 15130.9 & 407 & 0 \\
Water & 2831.5 & 707.9 & 530.9 & 13715.2 & 18033.2 & 26.5 \\
Soil & 3450.9 & 1725.5 & 1291.9 & 1513.1 & 8.8 & 17.7 \\
Waste & 1159.2 & 1159.2 & 1451.2 & 16086.6 & 16086.6 & 8.8 \\
Biological & 2884.6 & 964.5 & 628.2 & 2212.2 & 2203.3 & 300.8 \\
Food & 88.5 & 265.5 & 884.9 & 265.5 & 88.5 & 8.8 \\
Raw & 2300.6 & 44.2 & 88.5 & 61.9 & 8.8 & 0 \\
Entertainment & 1132.6 & 35.4 & 8.8 & 4910.9 & 40676.4 & 8.8 \\
\hline
\end{tabular}


Table 2. Regional ecological footprint, ecological bearing capacity and the compensation amount

\begin{tabular}{|c|c|c|c|c|c|}
\hline Area & $\begin{array}{l}\text { The population of } \\
2008 \text { (ten thousand) }\end{array}$ & $\begin{array}{l}\text { Ecological footprint } \\
\text { (hm2/ten thousand) }\end{array}$ & $\begin{array}{l}\text { Ecological } \\
\text { carrying capacity } \\
\text { (hm2/ten } \\
\text { thousand) }\end{array}$ & $\begin{array}{l}\text { The ecological } \\
\text { compensation } \\
\text { amount (¥ ten } \\
\text { thousand) }\end{array}$ & $\begin{array}{l}\text { Proportion } \\
\text { of GDP }\end{array}$ \\
\hline East & 47964 & 19487.13 & 12948.55 & -1543624.31 & $0.09 \%$ \\
\hline Northeast & 10874 & 4199.19 & 21320.96 & 6027985.56 & $2.13 \%$ \\
\hline Central & 70689 & 33178.34 & 32621.27 & -363690.98 & $0.06 \%$ \\
\hline Western & 36523 & 15768.35 & 30569.87 & 21299323.88 & $3.66 \%$ \\
\hline
\end{tabular}

